\title{
artigo
}

Nunes, Y.T.; Vicente, M.C.; Leite, R.B.S.M.; Simões, J.C.; Xavier, B.H.S.H.; Manola, C.C.V.; Melo, E.B.M.;

Construção de tecnologia educativa para o controle de infecção em serviços de saúde

\section{Construção de tecnologia educativa para o controle de infecção em serviç̧os de saúde}

\author{
Construction of educational technology for infection control in health services \\ Construcción de tecnología educativa para el control de infecciones en servicios de salud
}

\begin{abstract}
RESUMO
Objetivo: Descrever o processo de desenvolvimento de uma tecnologia educativa destinada a pacientes e profissionais de saúde com a finalidade de prevenção de infecção em serviços de saúde. Metodologia: Estudo metodológico desenvolvido em 2019 em duas etapas: seleção do conteúdo e construção da tecnologia educativa. Resultados: A tecnologia denominada "Prevenindo a todo tempo" tem na sua dimensão 10,5 x 14,8 cm, possui 7 páginas frente e verso, contendo: capa, painel informativo, sendo que a organização do conteúdo, a partir da página 3, foi organizado por meio de atividades lúdicas, sendo: jogo de labirinto, jogo dos sete erros, jogo da memória, caça palavras, jogo dos 5 momentos, cruzadinhas, figura direta e informações da sequência correta para higienização das mãos. Considerações Finais: 0 produto desta tecnologia espera- se despertar o conhecimento sobre a higienização, sendo assim, acarretar uma boa adesão nos serviços para que se busque uma melhor qualidade da assistência prestada.

DESCRITORES: Higienização das Mãos; Tecnologia Educativa; Infecção em Serviços em Saúde.
\end{abstract}

\section{ABSTRACT}

Objective: To describe the process of developing an educational technology for patients and health professionals with the purpose of preventing infection in health services. Methodology: Methodological study developed in 2019 in two stages: selection of content and construction of educational technology. Results: The technology called "Preventing at all times" has a dimension of $10.5 \times 14.8$ $\mathrm{cm}$, has 7 front and back pages, containing: cover, information panel, and the organization of the content, starting on page 3 , was organized through ludic activities, being: maze game, game of seven errors, memory game, word search, game of 5 moments, crosswords, direct figure and information of the correct sequence for hand hygiene. Final Considerations: The product of this technology is expected to awaken knowledge about hygiene, thus, leading to good adherence to services so that better quality of care is sought. DESCRIPTORS: Hand Hygiene; Educational Technology; Infection in Health Services.

\section{RESUMEN}

Objetivo: Describir el proceso de desarrollo de una tecnología educativa para pacientes y profesionales de la salud con el propósito de prevenir infecciones en los servicios de salud. Metodología: Estudio metodológico desarrollado en 2019 en dos etapas: selección de contenidos y construcción de tecnología educativa. Resultados: La tecnología denominada "Prevenir en todo momento" tiene una dimensión de 10,5 x 14,8 cm, consta de 7 portadas y contraportadas, que contienen: portada, panel informativo y organización del contenido, a partir de la página 3, se organizó a través de actividades lúdicas, siendo: juego de laberinto, juego de siete errores, juego de memoria, búsqueda de palabras, juego de 5 momentos, crucigramas, figura directa e información de la secuencia correcta para la higiene de manos. Consideraciones Finales: Se espera que el producto de esta tecnología despierte conocimientos sobre higiene, conduciendo así a una buena adherencia a los servicios para que se busque una mejor calidad de atención.

DESCRIPTORES: Higienización de Manos; Tecnologia Educacional; Infección en los Servicios de Salud.

RECEBIDO EM: 07/06/2020 APROVADO EM: 07/06/2020

\author{
Yngrid Toniato Nunes \\ Enfermeira do Serviço de Controle de Infecção do Hospital Meridional. \\ ORCID: 0000-0003-3428-733X
}

\section{Marcelo Costa Vicente}

Enfermeiro, mestre em saúde coletiva - Faculdades Integradas São Pedro.

ORCID: 0000-0002-5518-2900 


\section{Rozeli Brandão da Silva Mendes Leite}

Enfermeira do Hospital Universitário Cassiano Antônio de Moraes HUCAM.

ORCID: 0000-0002-3086-3136

\section{Jeremias Campos Simões}

Enfermeiro. Doutorando em enfermagem pela Universidade Federal do Espírito Santo, docente do Centro Universitário Salesiano. ORCID: 0000-0002-3970-0819

\section{Bárbara Heloisa Soares Heringer Xavier}

Enfermeira docente da escola politécnica do Brasil.

ORCID: 0000-0001-8792-8909

\section{Claudia Curbani Vieira Manola}

Enfermeira mestre em administração e docente do Centro Universitário Salesiano. ORCID: 0000-0002-0925-4432

\section{Evandro Bernardino Mendes de Melo}

Enfermeiro. Doutorando em Enfermagem na Universidade Federal de Minas Gerais. MS, Brasil e docente do Centro Universitário Salesiano.

ORCID: 0000-0002-1772-3083

\section{INTRODUÇÃO}

A educação em saúde constitui uma ferramenta bastante utilizada por enfermeiros, principalmente quando se almeja mudanças relacionadas a hábitos que visam a diminuição dos riscos de infecções diversas adquiridas em serviços de saúde. Dentre as medidas mais utilizadas para promoção e educação em saúde, podemos citar os materiais impressos bastante utilizados para melhorar o conhecimento e a auto responsabilização do paciente frente à sua saúde. Estudos recomendam a utilização de materiais impressos para reforçar orientações verbais, sabe-se que esses materiais auxiliam nas possíveis dúvidas do paciente, contribuindo com informações seguras e atemporais na ausência de um profissional em saúde ${ }^{(1-5)}$.

$\mathrm{O}$ enfermeiro atua como agente de educação em saúde desenvolvendo materiais educativos que possam auxiliá-lo no processo de ensino e aprendizagem de pacientes. Tais recursos educativos permitem interações entre o enfermeiro, o paciente e seu familiar, e o objeto a ser compreendido. Cabe ressaltar, então, que os materiais impressos requerem objetivos educacionais claros a ser atingidos pelo público alvo. Nesse sentindo, a abordagem participativa multiprofissional na construção destes se faz necessária para o desenvolvimento de materiais impressos de qualidade que permitam identificar as necessidades do público alvo, correspondendo, ao mesmo tempo, à necessidade dos serviços de saúde ${ }^{(3-5)}$.

Autoridades nacionais e internacionais de saúde recomendam a segurança do paciente como um quesito prioritário na prestação de serviços. Sabe-se que é de responsabilidade do enfermeiro e de sua equipe prestar uma assistência à pessoa, à família e à coletividade, livre de danos decorrentes de imperícia, negligência ou imprudência. No Brasil, essa tendência está regulamentada por meio do Programa Nacional de Segurança do Paciente, cujo objetivo é implementar medidas assistenciais seguras em diferentes áreas de atenção à saúde. Dentre essas medidas, podemos citar a higienização das mãos, considerada a principal conduta profissional de prevenção de infecção em serviços de saúde ${ }^{(6-8)}$.

Estudos mostram que as mãos constituem o principal meio de interligação entre os profissionais de enfermagem e o paciente. Sendo assim, a prática da higienização das mãos reduz significantemente a transmissão de micro-organismos e, consequentemente, a incidência das infecções preveníeis, reduzindo a morbimortalidade em serviços em saúde. Entretanto, a literatura aponta que a falta de adesão ao procedimento de higienização das mãos ainda é uma lacuna a ser sanada ${ }^{(9,10)}$. Diante dessa realidade, a presente pesquisa se propôs à elaboração de uma tecnológica educativa para o controle de infecção em serviços em saúde.

\section{METODOLOGIA}

Trata-se de um estudo metodológico constituído por duas etapas: 1) Seleção do conteúdo e 2) Construção da tecnologia educativa. A cartilha educativa denominada "Prevenindo a todo tempo" foi desenvolvida conforme os seguintes quesitos: conteúdo e linguagem, organização, layout, ilustração, a formas de motivação e aprendizagem. Desta maneira, a elaboração da cartilha informativa traduziu-se em oportunizar aos pacientes e acompanhantes conhecimentos relacionados à higienização das mãos e à prevenção de infecções em serviços de saúde.

No processo de construção da cartilha informativa, foi realizado o levantamento bibliográfico por meio de diretrizes do ministério da saúde, dentre os quais citam-se: os manuais da Agência Nacional de Vigilância Sanitária (ANVISA), os guias de segurança do paciente e alguns formulários de boas práticas assistências na prevenção de infecção relacionada aos serviços de saúde.

Assim, considerando a especificidade da tecnologia desenvolvida, o trabalho de design, a diagramação das imagens, o layout, 


\section{artigo}

Nunes, Y.T.; Vicente, M.C.; Leite, R.B.S.M.; Simões, J.C.; Xavier, B.H.S.H.; Manola, C.C.V.; Melo, E.B.M.;

Construção de tecnologia educativa para o controle de infecção em serviços de saúde

a sensibilidade cultural, adequação à população alvo e cores e tamanho da cartilha informativa, contou-se com o trabalho de um profissional de design gráfico. As imagens foram captadas e, posteriormente, adaptadas no programa Adobe Ilustrator.

A versão da cartilha denominada "Prevenindo a todo tempo" tem na sua dimensão $10,5 \times 14,8 \mathrm{~cm}$, possui 7 páginas frente e verso, contendo: capa, painel informativo, sendo que a organização do conteúdo, a partir da página 3 , foi organizado por meio de atividades lúdicas, sendo: jogo de labirinto, jogo dos sete erros, jogo da memória, caça palavras, jogo dos 5 momentos, cruzadinhas, figura direta e informações da sequência correta para higienização das mãos.

Logo após as revisões textuais, buscando classificar o grau de facilidade na leitura dos textos apresentados, calculou-se o ILF (Índice de Legibilidade de Flesch), o qual avalia o grau de legibilidade dos textos em uma escala porcentual de zero a cem conforme a seguinte fórmula: 206.835 - (1.015 x ASL) - (84,6 x ASW), onde ASL significa cumprimento médio da sentença - o número de palavras dividido pelo número de sentenças, já ASW significa número médio de silabas por palavra - o número de silabas dividido pelo número de palavras. Cabe ressaltar que por se tratar de uma tecnologia que será validada futuramente quanto ao conteúdo e aparência, o presente estudo foi submetido ao Comitê de Ética de Pesquisa do Centro Universitário Católico de Vitória (UCV) obtendo aprovação sob número de CAAE 19271019.0.0000.5068.

\section{RESULTADOS E DISCUSSÃO}

Com base no método abordado, incialmente foi realizada a seleção do conteúdo que serviu como base para a construção da tecnologia proposta, considerando como fontes artigos científicos, manuais do Ministério da Saúde e Livros, dentre outros descritos abaixo:

\section{Quadro 1. Livros contemplados na revisão de literatura. Vitória, ES, Brasil, 2019}

\section{CONTEÚDO SELECIONADO}

Segurança do paciente Higienização das mãos.

Resolução da diretoria colegiada -RDC N 50

Resolução de diretoria colegiada - RDC N 36

Protocolo para a prática de higiene das mãos em serviços de saúde.

Guia para a Implementação da Estratégia Multimodal da OMS para a Melhoria da Higiene das Mãos

Assistência Segura: Uma Reflexão Teórica Aplicada à Prática. Série Segurança do Paciente e Qualidade em Serviços de Saúde

Higienização das mãos como prática do cuidar: reflexão acerca da responsabilidade profissional

World Health Organization

Estratégia lúdica para a melhoria de práticas de higienização das mãos entre os profissionais de saúde.

\section{FONTE:}

Agência Nacional de Vigilância Sanitária (Ministério da Saúde). Acesso em: 05 de nov. de 2019. Disponível em: <http://www.anvisa.gov.br/servicosaude/manuais/paciente_hig_maos.pdf>

Agência Nacional de Vigilância Sanitária (Ministério da Saúde). Acesso em: 05 de nov. de 2019. Disponível em: <http://bvsms.saude.gov.br/bvs/saudelegis/ anvisa/2002/res0050_21_02_2002.html>

Agência Nacional de Vigilância Sanitária (Ministério da Saúde). Acesso em: 05 de nov. de 2019. Disponivel em: <http://bvsms.saude.gov.br/bvs/saudelegis/ anvisa/2013/rdc0036_25_07_2013.html>

Agência Nacional de Vigilância Sanitária (Ministério da Saúde). Acesso em: 05 de nov. de 2019. Disponivel em: <file:///C:/Users/Familia/Downloads/protoc_ higieneDasMaos.pdf>.

Agência Nacional de Vigilância Sanitária (Ministério da Saúde). Acesso em: 01 de nov. de 2019. Disponível em: <http://www.anvisa.gov.br/servicosaude/controle/higienizacao_oms/guiade_implement.pdf>.

Agência Nacional de Vigilância Sanitária (Ministério da Saúde). Acesso em: 01 de nov. de 2019. Disponivel em: <http://portal.anvisa.gov.br/ documents/33852/3507912/Caderno+1+-+Assistencia+Segura++Uma+Reflexao+Teorica+Aplicada+a+Pratica/97881798-cea0-4974-9d9b-077528ea1573>.

Belela-Anacleto ASC, Peterlini MAS, Pedreira MLG.. Rev Bras Enferm [Internet]. 2017;70(2):442-5. DOl: http://dx.doi.org/10.1590/0034-7167- 20160189. Acesso em: 01 de nov. de 2019. Disponível em: <http://www.scielo.br/ pdf/reben/v70n2/pt_0034-7167-reben-70-02-0442.pdf>.

WHO. Hand Hygiene: Why, How and When. SummaryBrochure on Hand Hygiene. World Alliance for Patient Safety, 2006. p. 1-4. Acesso em: 01 nov. 2019. Disponivel em: <https://apps.who.int/iris/bitstream/handle/10665/44102/9789241597906_eng.pdf;jsessionid=232884196B5CD9A317CBE262D9972EE4?sequenc $\mathrm{e}=1$.>.

Rev enferm UFPE on-line., Recife, 11(10):3971-9, out., 2017. Acesso em: 01 de nov. de 2019. Disponivel em: <file:///C:/Users/Familia/Downloads/ 25207-69766-1PB\%20(1).pdf>. 
Para a construção da cartilha informativa, utilizou-se a experiência da autora adquirida durante o estágio acadêmico realizado no Serviço de Controle de Infecção Hospitalar (SCIH) de um Hospital Geral Privado localizado no Município de Caríaci$\mathrm{ca} / \mathrm{ES}$. Observou-se que os pacientes permaneciam ociosos por um longo período enquanto aguardavam procedimentos cirúrgicos, marcação de consultas ou mesmo por internação prolongada. Nessa perspectiva, pensou-se em elaborar uma cartilha informativa lúdica que pudesse servir como instrumento mediador do conhecimento para mudança de atitude frente ao hábito de higienização das mãos.

Após a seleção do conteúdo, a cartilha foi elaborada por um profissional web design e seguiu o tamanho portátil de $10,5 \times 14,8 \mathrm{~cm}$ equivalente ao formato A6. Esse tamanho é suficiente para proporcionar a uma boa leitura e interpretação dos jogos, podendo ser guardado dentro de uma bolsa, de modo que o usuário tenha a possibilidade de usá-lo posteriormente. As cores usadas e o tipo de ilustração foram pensados para deixar o material mais lúdico, menos formal e mais "divertido". Essa é uma estratégia que ajuda a conservar a atenção do usuário no material gráfico. As tipografias usadas foram a Cooper Black para os títulos em tamanho $11 \mathrm{pt}$ e a Trebuchet MS tamanho 10pt e entrelinha 12pt. Para o corpo do texto, optou-se por utilizar a Cooper Black nos títulos, por possuir traços arredondados e marcantes, uma vez que os títulos são foco de atenção no texto; já o corpo do texto se constitui por uma tipografia mais legível e com tamanho que permitisse uma boa leitura. As cores escolhidas para os fundos são frias e derivam de cores de um ambiente hospitalar, as cores das ilustrações são mais quentes e coloridas e contrastam com o fundo.

A capa foi criada com uma ilustração de uma mão sendo analisada por uma lupa, que identifica a presença de micro-organismos e a pergunta: Já higienizou
O processo de

higiene das mãos se

destaca como uma

das medidas mais

importantes para 0

controle de infecção

relacionada à

assistência à saúde.

E é umas das

formas mais de

baixo custo, com

uma boa eficácia

pela praticidade

e uns bons custos

beneficiam para

as infecções

relacionadas à

assistência à saúde suas mãos hoje? Repleto de interrogações. Um estudo ${ }^{(11)}$ constatou que as mãos são o principal fator de risco para transmissão de micro-organismos, de modo que se assegura a importância das higienização da mãos e reconhece, no seu estudo, que essa prática não é feita na maioria das vezes. Assim, o mesmo autor elaborou uma tecnologia lúdica para o envolvimento e de aspectos teóricos e práticos sobre higienização das mãos, contribuindo, com isso, para a melhoria da segurança do paciente. As infecções causadas por bactérias multirresistentes estão sendo bastante comuns, o que vem preocupando bastante as entidades, pois, com a resistência aos antimicrobianos, as bactérias só vêm se fortalecendo ${ }^{(6)}$.

O processo de industrialização e modernização trouxe avanços tecnológicos e, com isso, a valorização da ciência; para a área da saúde, a introdução da informática e de surgimento de aparelhos modernos e sofisticados que viabilizaram benefícios e velocidade na luta contra as doenças. Diariamente as inovações tecnológicas ocorrem de modo crescente e acelerado, disponibilizando aos profissionais e usuários diferentes tipos de tecnologia, sejam elas educacionais, gerenciais ou assistenciais ${ }^{(12)}$.

A concepção visual provoca no usuário um questionamento se a higienização das suas mãos foi feita de maneira adequada, as cores e o tipo de ilustração ajudam ao material ter certa leveza em abordar um assunto tão sério e instiga a leitura do material (figuras 1, 2, 3, 4, 5 e 6).

$\mathrm{O}$ processo de higiene das mãos se destaca como uma das medidas mais importantes para o controle de infecção relacionada à assistência à saúde. E é umas das formas mais de baixo custo, com uma boa eficácia pela praticidade e uns bons custos beneficiam para as infecções relacionadas à assistência à saúde ${ }^{(13)}$.

A higienização é uma das medidas comprovadas de baixo custo para a prevenção primária de infecções, além de promover uma boa estadia do paciente no ambiente hospitalar, não 


\section{artigo}

Nunes, Y.T.; Vicente, M.C.; Leite, R.B.S.M.; Simões, J.C.; Xavier, B.H.S.H.; Manola, C.C.V.; Melo, E.B.M.

Construção de tecnologia educativa para o controle de infecção em serviços de saúde

causando, assim, possíveis infecções, acarretando o prolongamento do indivíduo no hospital ${ }^{(14)}$.

O tema serviu de base para as ilustrações de bactérias e de micro-organismos identificados em uma lupa para que ficasse explícito que em uma mão existem bactérias. A falta da higienização das mãos faz parte da realidade da população brasileira. Afirma-se que já ocorreram surtos devido à não-higienização das mãos dos colaboradores de saúde, de modo que se identificaram vários micro-organismos. Existem diversos antissépticos e sabonetes que podem ser utilizados para a higiene das mãos durante o processo do cuidado dos pacien- tes $^{(6)}$. Um estudo ${ }^{(13)}$ constatou a possibilidade de transmissão de micro-organismo pelas mãos do profissional de saúde, ao passo que, com as medidas de higienização, reduzem-se as taxas de infecção após a adoção das medidas propostas, fazendo com que os profissionais alcancem eficácia na higiene das mãos e uma redução da carga microbiana deste indivíduo.

A versão desta tecnologia educativa contem doze páginas. A capa tem como uma ilustração de uma mão sendo analisada por uma lupa, que identifica a presença de micro-organismo fazendo com que desperte o público alvo à curiosidade e o interesse em conhecer a cartilha. $\mathrm{Na}$ pri- meira e segunda figuras, há informações para o público alvo: profissionais de saúde, paciente e acompanhantes que ficam ociosos, o que possibilita um bom entendimento sobre higienização das mãos e infecção hospitalar. A importância do comportamento das pessoas tem sido uma questão fundamental na prática dos profissionais envolvidos, é bastante importante a adesão e as recomendações da adesão aos protocolos. É fundamental que envolva a educação, para que haja mudanças e motivação no sistema, fazendo com que se criem estratégias para elevar esta adesão de higienização das mãos ${ }^{(6)}$.

Ainda na segunda figura, contém um

\section{Figura 1. Tecnologia "Prevenindo a todo tempo!". Vitória, ES, Brasil, 2019}
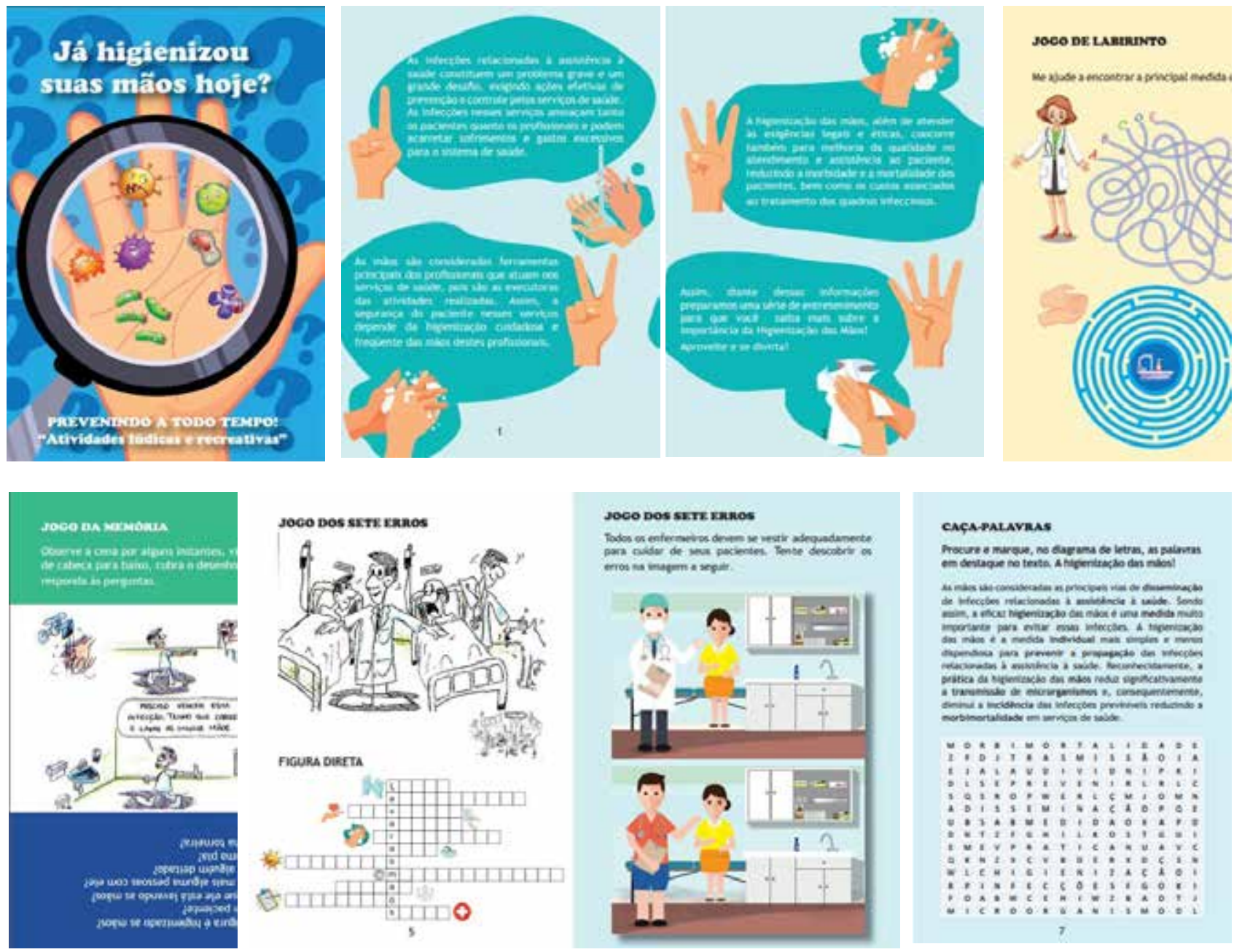

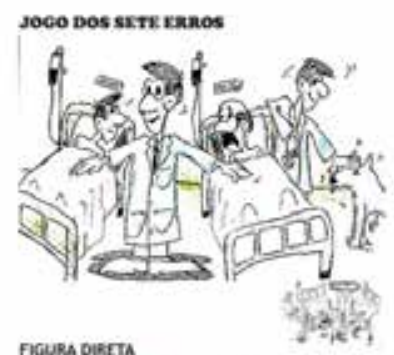

FIGURA DIKTTI

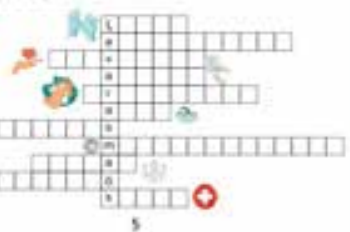

Joco DOS SETE ERnOS

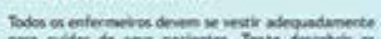

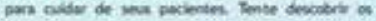

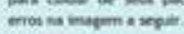
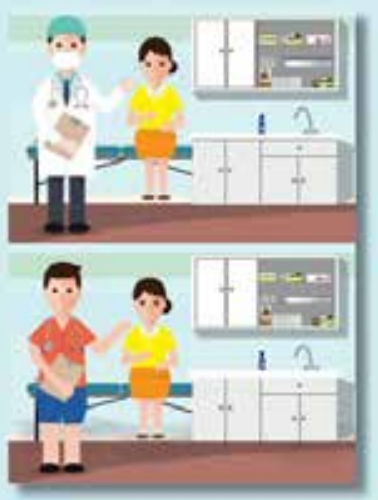

\section{caçarakans}

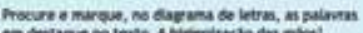

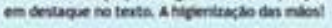

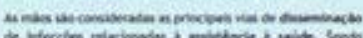

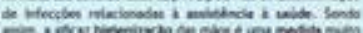

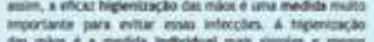

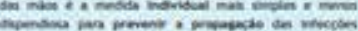

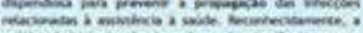

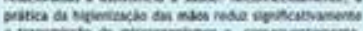

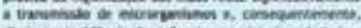

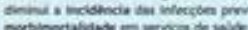

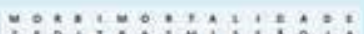

I:T;: :

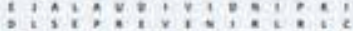

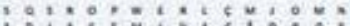

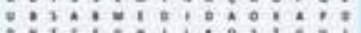

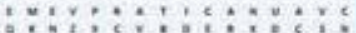

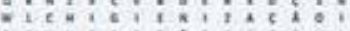

: : : : $: 5 ?:$ : : : : :

ic. $60 . \%$ 
jogo educativo lúdico através de um labirinto demonstrando os insumos para a higienização das mãos, isto é, sabão e água. Enfatiza-se a necessidade de higienizar as mãos e, principalmente, da disponibilidade de insumos necessários à prática, com fácil acesso, para pias e torneiras com acionamento automático para se ter uma boa adesão à higienização das mãos e outros possíveis ${ }^{(14)}$.

$\mathrm{Na}$ terceira figura, localiza-se uma cruzadinha com várias figuras envolvidas na biossegurança e na infecção hospitalar. Em seguida, há um jogo dos sete erros, figurado por um profissional tocando em personagens diferentes (ilustrando a falta de higienização das mãos entre um ato e outro). Por fim, propôs-se uma atividade chamada "figura direta". As infecçôes podem ser evitadas, sendo que os micro-organismos mais associados à transmissão são a microbiota transitória da pele, que pode ser adquirida por pessoas colonizadas ou infectadas e ao encostar-se em objetos contaminados. Essa infecção pode ser evitada pela higienização das mãos, pelo simples fato do ato mecânico, quando não é realizada pela forma adequada, pode ocorrer uma transmissão desses micro-organismos. Um estudo constatou que a microbiota transitória, localizada na superfície da pele por meio de fonte externa, pode ser facilmente removida através higienização das mãos pelo ato mecânico da fricção ${ }^{(15)}$.

$\mathrm{Na}$ quarta figura, foi ilustrado um jogo de sete erros em que seapresenta um enfermeiro com equipamentos de proteção individual. Há também um caça-palavras levando conhecimento e fixação sobre a higienização das mãos. Existem pesquisas que revelam o conhecimento do profissional de saúde da importância da higiene das mãos no controle de transmissão de micro-organismos e nos momentos que deveriam ser higienizados, mas, na prática, há um déficit, ocasionando um grande número de profissionais que não aderem à higienização das mãos no processo cuidar ${ }^{(13)}$.

Em relação à quinta figura, ela está indicando um jogo educativo de memória, representando os cinco momentos da higienização das mãos. No mesmo jogo, há um profissional de saúde indicando a prática correta da higienização, durante seu serviço. Afirma-se que todos os profissionais que trabalham nos serviços em saúde, que mantêm o contato direto ou indireto com o paciente (profissionais que atuam na alimentação ou manipulação de medicamentos, na manipulação dos materiais estéril ou contaminado), devem realizar a higiene das mãos em todas as suas oportunidades. Ainda os familiares, acompanhantes e visitantes também deverão ser orientados sobre a higienização antes e após o contato com os pacientes nos serviços de saúde ${ }^{(6)}$.

\section{Como a com água}

e sabonete comum:

quando houver

sujidade visível

ou exposição com

fluídos corpóreos,

antes e após as

refeições, após ir ao

banheiro, quando

iniciar e terminar

o seu turno de

trabalho.
$\mathrm{Na}$ sexta e última figura apresenta-se a técnica da higienização correta das mãos, de modo que o indivíduo pode aprender a técnica de forma correta. Enfatiza-se que as mãos dos profissionais dos serviços em saúde podem ser higienizadas por: água e sabonete comum, solução alcoólico e antisséptico degermante. E, com isso, a cada oportunidade tem uma especificação de quando usar estes produtos. Como a com água e sabonete comum: quando houver sujidade visível ou exposição com fluídos corpóreos, antes e após as refeições, após ir ao banheiro, quando iniciar e terminar o seu turno de trabalho. A Solução alcoólica: antes e após o contato direto com o paciente, depois de tocar em superfícies próximas, antes de realizar os procedimentos invasivos, ao mudar o sítio do contaminado para o limpo, após o risco de exposição de fluidos corpóreos. E, por último, a solução antisséptica degermante deve ser usada em casos de pacientes precauções por contatos, em casos de surtos, no pré-operatório (antes de qualquer procedimento cirúrgico), antes de qualquer procedimento invasivo (inserção de cateter venoso central, instalação de diálise, pequenas suturas ${ }^{(6)}$.

Uma boa higienização tem que seguir os passos da técnica (que pode ser variada dependendo do insumo que ela irá utilizar para a higienização), e a eficácia da técnica dependerá do tempo que o indivíduo irá realizar, antes de iniciar a técnica é necessário tirar os objetos das mãos (com anéis e pulseiras), pois os objetos podem estar colonizados por algum micro-organismo. A técnica utilizada para higiene das mãos pode ser comprometida pela equipe de enfermagem, pois na hora do cuidado não dão o devido valor à técnica e, assim, pulam etapas, fazendo com que essas falhas ao higienizar tenham uma consequência, como a disseminação de micro-organismos de um paciente para os outros, como também os ambientes e superfícies. Estudo $^{(16)}$ relata um problema de saúde pública, onde a ausência do dano do paciente é definida ao paciente durante o processo de cuidado, abrangindo, assim, uma promoção de assistência ineficaz. 


\section{artigo}

Nunes, Y.T.; Vicente, M.C.; Leite, R.B.S.M.; Simões, J.C.; Xavier, B.H.S.H.; Manola, C.C.V.; Melo, E.B.M.;

Construção de tecnologia educativa para o controle de infecção em serviços de saúde

\section{CONSIDERAÇÕES FINAIS}

Este estudo descreveu o desenvolvimento de uma tecnologia educativa denominada "Prevenindo a todo tempo", destinada aos pacientes, acompanhantes e profissionais assistenciais em serviços de saúde, para auxiliar sobre a temática higienização das mãos e sobre as infecções relacionadas à assistência à saúde. Seu conteúdo agrupa informações teóricas, jogos educacionais que se interliga para o aprendizado lúdico.

Posteriormente, pretende-se desenvolver a validação e a implementação da tecnologia educativa. Foi considerando o conhecimento técnico para a construção da tecnologia elaborada por um profissional web design. Espera-se que, com o produto desta tecnologia, seja despertado o conhecimento sobre a higienização, sendo possível, assim, acarretar uma boa adesão nos serviços para que se busque uma melhor qualidade da assistência prestada e que se reduzam as infecções relacionadas à assistência em saúde.

\section{REFERÊNCIAS}

1. Massaroli A, et al. Teaching of infection control in undergraduate courses in health sciences: opinion of experts. Rev. Bras. Enferm. [Internet]. 2018 [acesso em 10 nov 2019];71(Supl4):1626-1634. Disponivel em: http://www.scielo.br/scielo.php?script=sci_arttext\&pid=S0034- 71672018001001626\&Ing=en\&nrm=iso.

2. Alves DCl, Lacerda RA. Avaliação de Programas de Controle de Infecção relacionada a Assistência à Saúde de Hospitais. Rev. esc. enferm. USP [Internet]. 2015 Dec [acesso em 25 nov 2019];49(Spe):65-73. .Disponível em: http://www.scielo.br/scielo. php?script=sci_arttext\&pid=S0080- 62342015000700065\&lng=en\&nrm=iso >. Acesso em: 25 nov. 2019.

3. Silva IOAM, SILVA, et al. Cartilha sobre o prematuro como tecnologia educacional para família: estudo quase experimental. Acta paul. enferm. [Internet]. 2018 Jul [acesso em 01 nov 2019];31(4):334-341. Disponivel em: http:// www.scielo.br/scielo.php?script=sci_arttext\&pid=S010321002018000400334\&lng=en\&nrm=iso.

4. Freitas LR, et al. Guidebook for renal dialysis patients: care of central venous catheters and arteriovenous fistula. Rev. Bras. Enferm. [Internet]. 2019 Aug [acesso em 06 nov 2019];72(4):896902. Disponivel em: http://www.scielo.br/scielo.php?script=sci arttext\&pid=S0034- 71672019000400896\&lng=en\&nrm=iso.

5. Wild CF, et al. Validation of educational booklet: an educational technology in dengue prevention. Rev. Bras. Enferm.[Internet]. 2019 Oct [acesso em 20 nov 2019];72(5):1318-1325. Disponível em: http://www.scielo.br/scielo.php?script=sci_arttext\&pi$\mathrm{d}=$ S0034- 71672019000501318\&lng=en\&nrm=iso.

6. Agência Nacional de Vigilância Sanitária (BR). Segurança do paciente: higienização das mãos [Internet]. 2017 [acesso em 17 nov 2019]. Disponível em: http://www.anvisa.gov.br/servicosaude/manuais/paciente_hig_maos.pdf.

7. Conselho Federal de Enfermagem (BR). Resolução n. ${ }^{\circ}$ 564/2017. Código de Ética dos Profissionais de Enfermagem [Internet]. Brasilia (DF): COFEN, 2017 [acesso em 09 nov 2019]. Disponivel em: https://www.coren-df.gov.br/site/wp- content/ uploads/2019/09/projeto-codigo.pdf.

8. Agência Nacional de Vigilância Sanitária (BR). Programa Nacional de Segurança do Paciente: estado da arte e perspectivas [Internet]. Brasília (DF): ANVISA, 2015 [acesso em 25 nov 2019]. Disponível em: http://portalarquivos2.saude.gov.br/ images/pdf/2015/junho/03/2.c\%20-\%20Apresenta\%C3\%A7\%C3\%A30\%20PNSP\%20-\%20setembro_2013.pdf.
9. Fernandes DR, et al. Hand hygiene: knowledge and skill of caregivers in the hematopoietic stem cell transplantation. Rev. Bras. Enferm. [Internet]. 2019 Dec [acesso em 06 nov 2019];72(6):1653-1662. Disponivel em: http:// www.scielo.br/scielo.php?script=sci_arttext\&pid=S0034$71672019000601653 \& \operatorname{lng}=e n \& n r m=$ iso.

10. Faria LBG, et al. Knowledge and adherence os the nurse to standard precautions in critical units. Texto contexto - enferm. [Internet]. 2019 [acesso em 06 nov 2019];28:e20180144. Disponivel em: http://www.scielo.br/scielo.php?script=sci_arttext\&pid=S0104- 07072019000100353\&Ing=en\&nrm=iso.

11. Ribeiro FDO, Souza MA, Paula $A O$, et al. Estratégia lúdica para a melhoria de práticas de higienização das mãos entre os profissionais de saúde. Rev enferm UFPE on line [Internet]. 2017 out [acesso em 01 nov 2019];11910):3971-9. Recife, 11(10):39719, out., 2017. Disponivel em: https://pesquisa.bvsalud.org/portal/resource/pt/bde-33073.

12. Barra DCC, et al. Evolução histórica e impacto da tecnologia na área da saúde e da enfermagem. Rev Eletr Enferm [Internet]. 2006 [acesso em 17 nov 2019];8(3):422-430. Disponivel em: http://www.fen.ufg.br/revista/revista8_3/v8n3a13.htm.

13. Oliveira AC, Paula AO. Descalonamento de antimicrobiano e custos do tratamento de pacientes com infecção. Acta Paul Enferm [Internet]. 2012 [acesso em 17 nov 2019];25(2):68-74. Disponivel em: http://www.scielo.br/pdf/ape/v25nspe2/pt_11.pdf.

14. Jorge AM, Rached CDA. Adesão da equipe de enfermagem na higiene das mãos. Int J Health Manag Review [Internet]. 2018 [acesso em 17 nov 2019];2(4):1-11. Disponivel em: https:/l www.ijhmreview.org/ijhmreview/article/view/137.

15. Cordeiro VB, Lima CB. Higienização das mãos como ferramenta de prevenção e controle de infecção hospitalar. Temas em saúde [Internet]. 2016 [acesso em 17 nov 2019];16(2):425-444. Disponível em: http://temasemsaude.com/wp- content/uploads/2016/08/16224.pdf.

16. Belela-Anacleto ASC, et al . Higienização das mãos e a segurança do paciente: perspectiva de docentes e universitários. Texto contexto - enferm. [Internet]. 2013 Dec [acesso em 17 nov 2019];22(4):901-908. Disponível em: http:// www.scielo.br/scielo.php?script=sci_arttext\&pid=S010407072013000400005\&lng=en\&nrm=iso. 